Portland State University

PDXScholar

6-7-1995

\title{
The Effects of a Realistic Job Preview on an Applicant's Ability to Self-select into Organizations
}

Melissa Lynn Burton

Portland State University

Follow this and additional works at: https://pdxscholar.library.pdx.edu/open_access_etds

Part of the Psychology Commons

Let us know how access to this document benefits you.

\section{Recommended Citation}

Burton, Melissa Lynn, "The Effects of a Realistic Job Preview on an Applicant's Ability to Self-select into Organizations" (1995). Dissertations and Theses. Paper 4893.

https://doi.org/10.15760/etd.6769

This Thesis is brought to you for free and open access. It has been accepted for inclusion in Dissertations and Theses by an authorized administrator of PDXScholar. Please contact us if we can make this document more accessible: pdxscholar@pdx.edu. 


\section{THESIS APPROVAL}

The abstract and thesis of Melissa Lynn Burton for the Master of Science in Psychology were presented June 7, 1995, and accepted by the thesis committee and the department.

\section{COMMITTEE APPROVALS:}

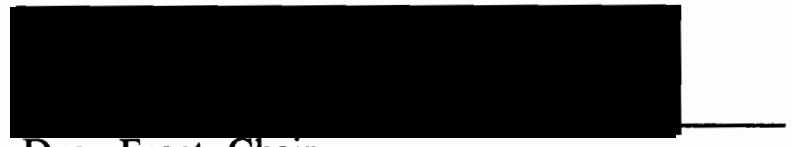

Dean Frost, Chair

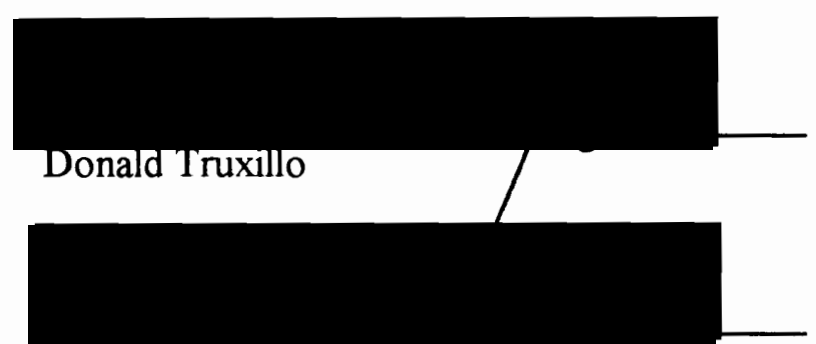

Peter Bullard

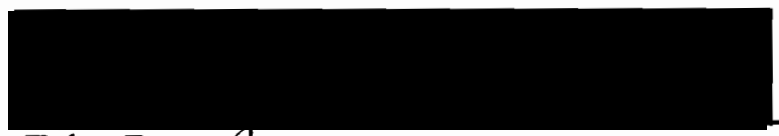

Talya Bauer

Representative of the

Office of Graduate Studies

\section{DEPARTMENT APPROVAL:}

James Paulson, Chair

Department of Psychology

\section{ACCEPTED FOR PORTLAND STATE UNIVERSITY}

BY THE LIBRARY

by

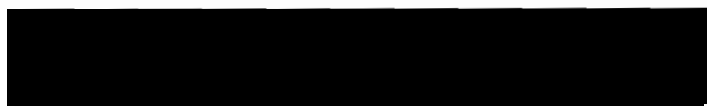

on

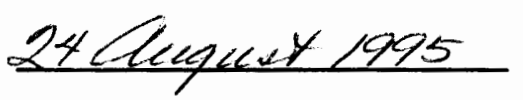




\begin{abstract}
An abstract of the thesis of Melissa Lynn Burton for the Master of Science in Psychology presented June, 7, 1995.
\end{abstract}

Title: The Effects of a Realistic Job Preview on an Applicant's Ability to SelfSelect Into Organizations.

In typical selection processes organizations gather information about an applicant. Rarely, however, do applicants collect equal information about the job or organization. This unequal exchange can inhibit an applicant's participation in the selection process. Studies have shown that realistic job previews (RJPs) positively influence applicants' job expectations, job satisfaction, turnover, selfselection, etc. Applicant self-selection can benefit both the organization and the applicant in terms of time, money, and energy required during the selection process and after organizational entry.

The purpose of the present study was to explore the relationship between RJPs and self-selection. The study assessed the influence of a content valid RJP on applicants' job expectations. It also measured the degree of fit between applicants' ideal job ratings and the job in question. This measure of fit was then related to the applicant's propensity to self-select. 
Twenty six applicants for an emergency 911 position participated. Each participant completed a Job Profile Measure consisting of three scales. These scales included ratings of job tasks (based on a job analysis), job characteristics (the Job Diagnostic Survey by Hackman \& Oldham, 1980), and organizational characteristics (the Organizational Culture Profile by O'Reilly, Chatman \& Caldwell, 1991). Applicants completed the measure before and after viewing the RJP and as a measure of ideal job requirements. Dispatch job incumbents also completed the measure to provide actual job ratings.

Results were limited by a small sample size, but several trends were found. T-tests showed that the RJP did not significantly alter applicants' job expectations. However, chi-square analyses indicated that applicant job task ratings were more consistent with incumbent ratings post RJP than pre RJP. MANOVA analyses indicated that applicant Job Profile ratings and incumbent ratings did not significantly converge after viewing the RJP. Self-selection ratings were also not significantly correlated with fit scores, but they were in the predicted direction. Applicant's with lower fit scores were more likely to self-select out of the hiring process. The trends in the data are encouraging, but more research is needed to be conclusive. 


\title{
THE EFFECTS OF A REALISTIC JOB PREVIEW ON AN APPLICANT'S ABILITY TO SELF-SELECT INTO ORGANIZATIONS
}

\author{
by \\ MELISSA LYNN BURTON
}

A thesis submitted in partial fulfillment of the requirements for the degree of

MASTER OF SCIENCE in PSYCHOLOGY

Portland State University

1995 
The Effects of a Realistic Job Preview on an Applicant's Ability to

\section{Self-Select Into Organizations}

Employee selection has been a topic of practical significance since the beginning of the century. Selection research has primarily focused on the "needs and goals of the user," where the user is defined as the organization (Landy, Shankster, \& Kohler, 1994, p. 278). Recently, however, there has been a shift towards considering applicants' perceptions of, and reactions towards, the selection process. Considering employee selection as a social process or as an interaction between the organization and the individual is turning the focus towards "the needs and goals of the test-taker" (Landy et al., 1994, p. 278; Rynes 1993b; Schuler, Farr, \& Smith, 1993).

Considering the perspective of the applicant in the selection process should prove to be beneficial to the organization in several ways. For instance, organizations can benefit from happy applicants in terms of organizational image and ease of recruitment. Likewise, they can suffer from unhappy ones (Landy et al., 1994; Rynes, 1993a; Schuler, et al., 1993). Schuler (1989) has further suggested that the most optimal selection decisions are a product of "an equitable or even joint decision process" (p. 40). This seems to be a potentially invaluable idea because selection is no longer comprised of only skill assessment. Instead, 
personnel decisions involve "whole person measurement," or the assessment of potential, attitudes, and personal characteristics (Offerman \& Gowing, 1993, p. 403 ). The complexity of these assessments makes the organization's job increasingly difficult. A selection process, therefore, which capitalizes on an applicant's own ability to select a job or organization would greatly supplement the traditional selection process.

To do this requires a fundamental change in the way personnel selection is done. For instance, in the typical selection procedure the organization gathers information about the applicant directly, via testing and interviews. The applicant, in contrast, discovers information about the job and organization indirectly through perceptions of the recruiter and marketing information (Rynes, 1993a). This methodology impinges on an equitable and joint decision making process which would require, at a minimum, an equal exchange of information between the organization and the applicant. Realistic job previews, or RJPs, provide one way of directly providing applicants with information about the job or organization to which they are applying. Furthermore, the research indicates that RJPs can be a valuable tool in enabling the applicant to self-select in or out of the hiring process. 
The purpose of this study was to explore the relationship between a realistic job preview and the process of self-selection. Specifically, it attempted to answer the following questions: Does the information provided by the RJP influence applicants' expectations about the job? If so, do applicants' expectations become more realistic after viewing an RJP? Lastly, do applicants use RJP information to self-select by assessing how similar the job is to their ideal job requirements? The pursuit of answers to these questions will lead to a better understanding of the role RJPs may play in creating a joint and equitable decision process.

The Realistic Job Preview

\section{What Does the RJP Do?}

Wanous (1980) has described the Realistic Job Preview (RJP) as a tool of selection or recruitment which helps an applicant assess an organization. Its purpose not being to "sell" an organization, but rather to "present outsiders with pertinent information" (Wanous, p. 37). Premack and Wanous (1985) summarized the RJP literature in a meta-analysis of 20 studies. They found that the RJP has been found to affect the following work outcomes: climate, commitment, coping, employment expectations, job satisfaction, job performance, self-selection, and job survival. 
Across studies presented in the meta-analysis, climate was a measure of applicants' perceptions of the organization. The RJP was predicted to increase positive affect towards the organization (e.g. the organization would be viewed as more honest, open, and supportive), but the mean effect size was not in the direction expected (-.02). The results were, however, limited by a small sample size.

The variable commitment, in most studies, was measured as the degree of organizational commitment. As expected, the results of the meta-analysis showed that a RJP improved commitment. The mean effect size of this variable was .19.

Coping, or applicants' perceptions of being able to handle the potential stressors of the job, was predicted to be positively influenced by the RJP. Specifically, an RJP should increase a person's preparedness for potential problems. However, this variable had a negative -.02 mean effect size which was not in the direction expected.. However, the small sample size was again problematic.

The meta-analysis indicated that employment expectations was a variable measured in a variety of ways across studies. For instance, one method measured the difference in applicants' expectations about various job and organizational factors between an RJP and control group. Another method was based on a met 
expectations index, or the comparison of pre-entry beliefs and post-entry beliefs. Both methods led to a mean effect size of -.34 . This was the highest effect size for all criterion variables in the meta-analysis. As expected, the results showed that RJPs significantly lowered applicants' initial expectations of the job.

Job satisfaction and job performance were also influenced by the RJP. Job satisfaction was measured in a variety of ways across studies. Overall the metaanalysis found that subjects who received realistic information were found to be more satisfied with their job. The overall mean effect size was .05 after removing an "outlying" or "extreme" study. Job performance was found to have a similar relationship to the RJP. For instance, ratings increased for those applicants who were exposed to a RJP with a mean effect size of .05 .

The variable self-selection was measured as the differential drop-out rate between the RJP and the control group. The RJP group was found to have a higher drop-out rate than the control group. The mean effect size was .12 after removing an outlying study.

The last variable, job survival, was a measure of the percentage of people who left the organization within a set amount of time from hire. In the metaanalysis, this variable was converted to the average stay in a job over the time frame specified. The results showed that those in the RJP group stayed in the job 
longer than those in the control group. The mean effect size was .12, one of the highest in the meta-analysis. This indicated that the RJP increased job survival. Six of the eight criteria had significant unexplained variance (all except climate and job survival). Therefore, the researchers looked for moderating variables. Only one variable, the medium used to present the RJP (written vs. audio-visual), was found. The moderating effect, however, was only on performance. Audio-visual RJPs led to higher job performance $($ effect size $=.32$ ), whereas written RJPs had a slightly negative effect on job performance (effect size $=-.04)$

Premack and Wanous (1985) qualified their conclusions by suggesting that it is important to understand possible interactions among the dependent variables. For instance, the employment expectations variable had the greatest mean effect size, but could be considered the only variable directly influenced by the RJP. In contrast, the other variables might not be independent of each other. The small effect sizes, therefore, could partially be explained by an interaction effect among the criterion measures. One such plausible interaction could be between job performance and applicant self-selection. If the variables were dependent, then the positive relationship found between the RJP and job performance could be due to the process of self-selection. In other words, poor performing applicants would 
have already eliminated themselves before being hired. This would thereby create a range restriction. The same conclusion could be drawn for job survival and selfselection. Job survival could, in fact, be considered as a post-entry measure of self-selection. Therefore, the positive relationship between the RJP and job survival could be due to the fact that when self-selection occurs prior to entry, it occurs less often post-entry as turnover. As before, there would be a range restriction problem with the job survival measure. Due to these possible interactions, the overall impact of the RJP could possibly be understated by any single criterion measure.

\section{What Should the RJP Look Like?}

\section{Method of Communication}

The literature has suggested that the RJP's effect depends on the medium of presentation. As noted in the Premack and Wanous (1985) study, the means of presenting the RJP was a significant moderating variable for job performance. Colarelli (1984) found that the method of communicating the RJP also influenced job survival. In this study, recently hired bank tellers were divided into three experimental groups and were presented an RJP. The first was a control group that was not given any special information. The second group was given a brochure that described the major job tasks and the positive and negative aspects 
of the job. The third group was given the opportunity to speak face-to-face with a job incumbent. There was a clear difference in turnover, 2-3 months after hire, between the face-to-face group and the other two groups. The face-to-face group experienced much less turnover. There was no difference, however, between the control group and the brochure group. The method of communication did not influence the tellers' job satisfaction or intention to quit after 1 year.

Saks and Cronshaw (1990) also found the effect of the RJP to be influenced by the method of communication. However, in their study the medium only influenced applicants' perceptions of the organization. Their subjects were undergraduate students who participated in an employment interview simulation. Each subject was randomly assigned to one of three conditions. The first condition served as the control group. These subjects received general job information regarding the history of the organization, the type of services provided, etc. They did not receive specific information about what might be expected on the job. The second group received specific job information in written form, and the third group received the same information during the interview orally. The study found that the method of communicating realistic information was not important when measuring change in job expectations. There was a change in applicant expectations in both the oral and the written RJP 
groups, but not in the control group. The method of communication was, however, important when measuring perception of interviewer and organization. The oral RJP was more effective than both the written RJP and the control group in creating positive impressions of the interviewer and the organization.

Two conclusions can be drawn from these studies. The first is that the choice of medium used in presenting the RJP depends on the purpose of the RJP. Changing applicants' expectations may only require written information, while changing applicants' affect for the organization may be better influenced by oral information. The second conclusion is that no matter how the RJP is presented, realistic information has an influence on work outcomes that general information (i.e. the control group) does not.

\section{RJP Content}

There has been little consensus regarding the content of RJPs. In fact, while most studies have implied that the RJP content was developed from job incumbents, few studies described specifically how the information was obtained (e.g., job analysis, interviews, questionnaires, etc.). In addition, "realism" has only been loosely defined in the literature. Low realism, for example, has been seen as favorable information, while high realism has been defined as a combination of unfavorable and favorable information (Gaugler \& Thornton, 
1990). Reilly, Brown, Blood, and Malatesta (1981) have suggested that this "lack of a clear operational definition of a RJP" (p. 832) has made the impact of RJPs difficult to interpret. They further stated that RJPs have been most effective when they are content valid. This would seem to ensure that the RJP's subject matter is appropriate and complete, while also ensuring a proper level of realism. Perhaps RJPs which were not content validated, may have created the modest and unexpected findings in the Premack \& Wanous meta-analysis (1985).

To ensure content validity, the RJP utilized in the present study was based on a job analysis conducted using the Job Element Method (JEM) (Primoff, 1975). The JEM method relied on incumbents to identify the knowledge, skills, abilities, and personal characteristics that differentiated superior workers from barely acceptable workers. The method involved both qualitative and quantitative processes. A panel of incumbents began by brainstorming elements (tasks) and subelements (KSAs) of the job in question. Each item was then rated by the incumbents on the following scales (see Appendix A for a rating form):

$\uparrow$ Barely Acceptable

$\downarrow$ Superior

$\uparrow$ Trouble

+ Practical
What portion of even barely acceptable workers are good in this element?

How important is this element in distinguishing superior workers from non-superior workers?

How much trouble would there be on the job if this element was ignored in the hiring process?

How practical is it to expect applicants to have this element? 
It appears that the specific method utilized in creating an RJP is relatively unimportant, but that content validity is crucial to the effectiveness of the RJP.

\section{Why Does the RJP Work?}

The Premack and Wanous (1985) meta-analysis indicated that the RJP influenced several outcome measures, but it did not provide evidence regarding why RJPs produced the results. Breaugh (1983) proposed the following four explanations about why RJPs work: met expectations, perception of organization, self-selection, and coping development. It should be noted that these four explanations support the interactions Premack and Wanous suggested. It should be further noted that self-selection was considered to be a criterion variable in the meta-analysis but a mediating variable by Breaugh.

Breaugh's (1983) met expectations theory posited that the realism of the information in an RJP would modify an applicant's normally unrealistic expectations about a job. More realistic expectations about the job would then affect job outcomes such as socialization, job survival, job performance, etc. The perception of organization explanation hypothesized that when organizations freely provide realistic information to an applicant, the organization would be perceived as more honest and open. The applicant might also interpret this as the organization affording them the opportunity to make an informed choice. These 
perceptions might explain why RJPs have been found to be positively correlated with organizational commitment. The self-selection hypothesis suggested that applicants utilize RJP information to determine their own suitability for the job. Applicants who do not perceive the job as suitable, are expected to drop out of the hiring process. Theoretically this would create a restricted range of hirees and thereby explain the positive relationship between RJPs and job performance or job survival. Lastly, the coping hypothesis proposed that RJPs provide a warning to applicants about potential problems and conflicts of the job. This warning would lead the applicant to prepare for the problems and develop coping strategies. These are all hypotheses, but in fact it is not yet clear why RJPs work. Nevertheless, it is evident that they effect many work outcomes valued by organizations.

\section{Self-Selection and the RJP}

As discussed previously, it has been postulated that RJP information leads to a process of self-selection. This occurs when job applicants voluntarily remove themselves from a hiring process. It is a decision "based on self-perceived aptitudes as well as on interests and values and on the 'fit' between these individual characteristics and the candidate's information and ideas about the organizations in question" (Trost \& Kirchenkamp, 1993, p. 312). I would propose 
that self-selection can occur both before and after organizational entry. Pre-entry self-selection transpires when applicants drop out of the hiring process, or turn down an extended offer. Post-entry self-selection is manifested in variables such as low commitment, low satisfaction, and turnover which occur shortly after organizational entry.

There are two reasons why the relationship between RJPs and selfselection must be understood. The first is that as pre-entry self-selection is maximized, post-entry self-selection will be minimized. This has important costsaving implications for organizations. The second reason is that pre-entry selfselection is critical to achieving a "joint and equitable" selection process. Selfselection allows the applicant to play an active role in the hiring decision process.

Self-selection is, however, not a clearly defined construct. For example, in the self-selection and RJP literature there has been disagreement about the role of self-selection in the hiring process. Premack and Wanous (1985) for instance, defined self-selection as a behaviorally based outcome measure; while other authors described it as a variable moderating the effect of the RJP on other outcomes (Colarelli, 1984; Saks \& Cronshaw, 1990; Suszko \& Breaugh, 1986).

Self-selection has also been a poorly measured construct. In the RJP literature it has primarily been measured in one of two ways. The first method has 
tested subjects who have been offered a job first, and then shown a RJP. Selfselection in this method has been a measure of the overall applicant acceptance rate (Colarelli, 1984; Suszko \& Breaugh, 1986; Wanous, 1973). This type of assessment has proven problematic because asking an applicant if they accept an already offered job is not indicative of the true influence of the RJP. Having received a job offer implies that the applicants have significantly invested themselves in the process and rejecting an offer might cause significant cognitive dissonance. Furthermore, decision making theory suggests that the job being offered would be weighted greater in their decision than possible future options because it is a certain reality compared to uncertain possibilities (Kahneman \& Tversky, 1979). Measuring self-selection in this way, therefore, inevitably undermines the purpose of the RJP as a "screening device...for those who would be most likely to quit as a result of a poor match" (Wanous, 1973, p. 328).

The second method has asked subjects about the likelihood of their accepting employment "should" they be offered a job (Gaugler \& Thornton, 1990; Saks \& Cronshaw, 1990). This has also been problematic because the subjects have often been students offered "simulated" jobs, as in the studies by Gaugler and Thornton and Saks and Cronshaw. In addition, the measure of self-selection has often been based on a single response item such as "How likely is it that you 
will accept this job," (Saks \& Cronshaw) or "Will you accept a job offer if one is made" (Gaugler \& Thornton). These questions ask for dichotomous responses and rarely for interval responses.

Self-selection based on expected utility theory would reduce these measurement problems. This theory postulates that people make decisions by assessing the utility of each option. Utility is derived from combining the value of each alternative and the probability of achieving that outcome (Lichtenberg, Shaffer, \& Arachtingi, 1993). Lichtenberg, et al. (1993) demonstrated the use of this model in a study in which college students completed a work values inventory. The inventory asked the subjects to rank 15 different work-related values. Subjects were then asked to rate 18 occupations on the likelihood that each job would satisfy their previously defined work values. The final expected utility score for each occupation was the sum of the "desirability of each of the 15 work values weighted by the subjective probabilities associated with the work values given the specific career" (p. 243).

Vroom (1966) used utility theory in a study on organizational choice. He hypothesized that the degree to which a subject was attracted to an organization was related to the extent the organization was seen as instrumental to the attainment of personal goals. Subjects rated a set of goals using a Q-sort method. 
They then rated several organizations on a scale of instrumentality which asked them to decide how likely it was that each goal would be attained from the respective organization. He found that $76 \%$ of organizational choice decisions were predicted from an index which measured the strength of the relationship between goal importance and organizational instrumentality.

Measuring self-selection based on expected utility would explicitly account for two factors that the other methods only implicitly considered. First of all, it bases the decision on what is important to the applicant and second of all, it provides an estimation of how likely it is that the organization or job is congruent with those values. Measuring self-selection in this way is compatible with the definition of self-selection presented earlier. It explicitly accounts for a type of matching process in which the applicant assesses the congruence between themselves and the job or organization.

Understanding self-selection as a matching process reinforces the important role that the RJP plays in selection. For instance, although applicants bring to the hiring process of set of ideal requirements (goals, values, etc.), they also bring expectations about the job or organization. Without a RJP those expectations may remain unrealistic until after organizational entry. The RJP, 
therefore, is critical in ensuring that an applicant makes an accurate and early selfselection decision.

\section{Person-Job "Fit"}

Matching individuals and jobs has been proposed in many areas of research. For instance, vocational theories suggest that individuals should choose vocations which are consistent with their self-concept (Holland, 1985; Myers \& McCaulley, 1985; Super, 1957). In addition, job acceptance rates have been found to coincide with applicants' expectations that a job or organization will meet their needs, values, and goals and be consistent with their self concepts (Cherniss, 1980; Hackman \& Oldham, 1980; Posner, 1981; \& Wanous, 1980). The literature has described this process as an assessment of "fit." O'Reilly, Chatman, and Caldwell (1991) have suggested that fit is established in the idea that an individual's characteristics combine with situational characteristics to produce an outcome. When there is congruence between individual and situational characteristics, i.e. a fit, the outcomes are positive. When there is a mismatch, either between the person and the vocation or between the person and organization, the outcomes are negative.

Cherniss (1980) looked at the fit between personal career orientation and work settings. He defined career orientation as the "meaning of work for the 
individual" (p. 189) and delineated four career orientations found in public professionals: Social Activists, Careerists, Artisans, and Self-Investors. All four orientations were based on the work of Wilensky (1956) and were defined by different goals and values. For instance, the Social Activists, had the primary work objective of bringing about "social and institutional change" (p. 191). Careerists, in contrast, found purpose in terms of prestige, respect, financial rewards, and success.

The study was based on interviews with 25 public professionals and found that "there was an optimal work setting (for each orientation), and the degree of stress, strain, and burnout was influenced by the goodness of fit between individual career orientation and work setting" (Cherniss, 1980, p. 191). He also found that when there was a bad fit, (i.e., one's orientation did not match the demands of the job), some change eventually took place. For example, some subjects changed their orientation while others changed their job demands. Nonetheless, the most satisfied subjects were those that chose a job that fit their orientational goals.

Burke and Deszca (1988) found similar results with a larger sample. They utilized the same four orientations and studied 295 police workers. Each subject identified a narrative description of the orientation that best described them. They 
then rated the similarity between their job and work characteristics that have been identified as precursors to stress and burnout. They found that Self-Investors, those who have non-work priorities, reported significantly more negative work characteristics (workload, autonomy, social isolation, etc.) than did Careerists and Artisans. Self-Investors were also significantly less satisfied with their jobs, reported more burnout, and were more likely to quit (intentions) than were other orientations. The authors concluded that the results were due to a lack of fit, and that Self-Investors simply did not fit the police occupation. While the results of this study are certainly not generalizable to other occupations, they do suggest that a fit between a person and a work environment is important.

O'Reilly, Chatman, and Caldwell (1991) developed the Organizational Culture Profile (OCP) to assess person-organization fit. It is based on the idea that the dimensions of personal organizational values actually exist as organizational cultures. This has allowed people and situations to be described in similar terms, on similar dimensions.

The OCP measures "the central values that may be important to an individual's self-concept or identity as well as relevant to an organization's central value system" (O’Reilly et al., 1991, p. 493). It was developed using a Qsort profile comparison process which required subjects to sort 54 value 
statements into nine categories (Chatman, 1991). The instructions asked subjects to think about the importance of each value as a part of their ideal organization's value system. Organizational members were also asked to determine those values that characterized the organization for which they worked. The degree of fit equaled the correlation between the individual profile and the organizational profile.

Chatman (1991) utilized the OCP in a study in which she investigated the development and maintenance of person/organization fit during a two and onehalf year period. Her subjects were audit staff members of eight of the largest U.S. public accounting firms. First she had subjects complete the OCP during the orientation sessions as new employees of the firms. Then subjects were asked to complete several independent measures including: an adjective check list, information regarding connection with firm incumbents before hiring, information about their job search process (number of applications sent out, offers received, etc.), and a self monitoring scale. Subjects were again questioned 10-12 months after hire. During this follow-up period of data collection, subjects completed: the OCP, a socialization scale (measure of actual interaction with firm members), perceptions of socialization scale (measure of their firm on socialization tactics), overall satisfaction, and intent to leave. 
Results indicated that applicants who entered the firm with a high degree of fit often had more similar values to incumbents. The degree of fit was also related to the amount of time the hirees spent with incumbents before entry. In addition, high fit at entry was positively associated with satisfaction one year later and negatively associated with intent to leave 2 and one-half years later. Fit measures at time 2 were positively related to participation in firm-related social events and time with mentor, but not with socialization perceptions or with training.

These results suggested that applicants not only assess fit during selection, but that it also gets shaped during socialization. It also appeared that fit was primarily affected by personal contact during socialization, not by formalized training. Nonetheless, the results clearly indicated the importance of fit assessment. As the author suggested, "job seekers should explicitly gather information about prospective organizations' values before deciding to join, perhaps by asking questions that reveal organizational values" (Chatman, 1991, p. 480).

The Purpose of The Present Study

The primary purpose of the present study was to investigate the relationship between RJPs and the process of self-selection. This investigation 
contributed improvements or innovations to the RJP literature such as: the content of the RJP, the medium used for the RJP, and the assessment of selfselection.

The RJP in this study was intended to provide applicants with information they would compare to their ideal job. This comparison was expected to be an assessment of fit between the applicant and the job/organization. The RJP, therefore, was designed to provide as much information about the job as possible. The RJP provided a complete profile of the job, including: information about job tasks, characteristics of the job, and information about the organization. The RJP content was also based on a job analysis and SME input. It was therefore considered to be content valid, an improvement over past research.

The RJP was presented via videotape because audio-visual communication seemed to combine the ease of administration of the brochure with the reality of face-to-face interviews. Furthermore, it provided a very real and very believable profile of the job because it was presented by job incumbents.

The literature has shown that RJPs can lead to a higher drop-out rate of applicants (self-selection). It is unknown exactly why this occurs, but it has been suggested that the applicants who self-select out of the hiring process find that the job does not meet their expectations. The measure of self-selection used in this 
study avoided the problems identified with previously used measures. For instance, the measure utilized multiple scaled questions which asked about intentions. The questions were designed to account for the applicant's expected utility of the job.

The specific hypotheses were as follows:

1. Applicant expectations about the dispatch job before viewing the RJP will be significantly different from expectations about the job after the RJP. The difference will emerge on all three job dimensions: job tasks, job characteristics, and organizational climate.

2. There will be a significant difference between applicant job ratings before the $\mathrm{RJP}$ and incumbent ratings on all three dimensions: tasks, characteristics, and climate.

3. There will not be a significant difference between applicant job ratings after the RJP and incumbent ratings on any job dimension.

4. Applicants whose ideal job requirements closely match incumbent ratings, i.e. those for which there is greater fit, will be less likely to self-select out of a job application process than those applicants with less similarity between ideal and incumbent ratings (less fit). 


\section{Method}

\section{Participants}

The participants were applicants for the Dispatcher I Emergency Services position at the Washington County Central Communications Agency (WCCCA). This is an entry-level position requiring a high school degree. The sample size was small, with a total of 26 participants. In this sample, $65 \%$ of the participants were female, $27 \%$ male, and $8 \%$ did not respond to the gender question. The large percentage of females was expected based on the current gender ratio of dispatchers. The mean age of the participants was 32, with the youngest being 19 and the oldest 47 . However, $30 \%$ of the participants did not indicate their age. All participants were high school graduates, $58 \%$ indicated that they had some college experience (including business or technical school), and $31 \%$ indicated that they had a college degree (including associate's and bachelor's degrees, and graduate study). Of the participants, $19 \%$ were current or past students in a Emergency Dispatch Program. Many of the participants, 54\%, indicated that they had actively been looking for a job for $0-3$ months, $17 \%$ indicated it had been between 4-6 months, $19 \%$ said it had been longer than 6 months, and $10 \%$ did not respond to this question. 
Solicitation of participants was done in conjunction with the announcement of testing by WCCCA. Applicants received a letter asking for their participation in the research study along with the letter announcing the testing (see Appendix B). The research letter explained the intent, process, time commitment, confidentiality, and potential benefits of the research. The agency has an open application process and collects approximately 150-200 applications before each testing period. It was expected that approximately 75-100 participants would be procured for this study but only 53 applicants were tested. Of these applicants, 26 agreed to participate in this study.

Data were collected from 40 dispatch incumbents. Each incumbent anonymously and voluntarily completed the job profile measure during working hours.

\section{Measures and Materials}

\section{Demographic Questionnaire (Appendix C)}

Participants were asked to provide the following demographic information: name, address, age, gender, and educational level. They were also asked to indicate the length of time they had been actively looking for a job and if they had been a student in a dispatch program. Each participant's name and address was kept separate from the other demographic information. 


\section{Job Profile Measure (Appendix D)}

The Job Profile Measure is composed of three separate scales that were selected to provide a complete profile of the dispatcher's job. The scales rate job tasks, job characteristics, and organizational climate. The Job Profile measure was completed by both participants and incumbent dispatchers. Participants completed it three times rating each of the following: their ideal job, their expectations of the dispatch job prior to viewing the RJP, and their expectations of the dispatch job after viewing the RJP. Incumbents completed the measure once, rating their actual job. Each scale is described below, along with a description of the various instruction sets. However, only the applicant pre-RJP version is provided in the designated appendices.

Job Tasks (Appendix D, page 68). This scale was based on a recent job analysis conducted according to the Job Element Method (Primoff, 1975) described earlier. The scale consisted of twenty task items which were selected according to two criteria. First, two subelements were selected to represent each of the 10 major job elements identified in the job analysis. Second, one of the subelements had a high performance score (above the mean), and one of the items had a low performance score (below the mean). The performance score is a measure of relative importance of the subelement and is calculated as the sum of 
the superior rating minus the barely acceptable rating plus the trouble is likely rating. In other words, the performance score indicates that an item is important in the job if it: a) discriminates between superior and barely acceptable workers and b) if it is critical to the job. All items appeared in a random order. Utilizing items with high and low performance scores ensured that the scale included not only relevant and important tasks, but also items that served as distractors. The high performance score items were classified as non-distractors while the low items were considered distractors.

Responses were provided on a five-point Likert scale of importance. The higher the rating the more important the task was considered in the job. Three instruction sets were used. Participants were asked to rate the importance of each task in their ideal job, and the expected importance of the task in the dispatcher job. The third version, for incumbents, asked how important each task was in their job as dispatcher. A mean score was obtained for the 10 distractor items and for the 10 non-distractor items.

Job Characteristics (Appendix D, pages 66-67). The Job Diagnostic Survey (JDS) and the Job Rating Form (JRF) (Hackman and Oldham, 1980) were used to measure applicants' perceptions of job characteristics. The JDS was designed for incumbents, and the JRF was designed for outsiders to the job. The 
short versions were used in this study and the questionnaires were based on seven, three item scales. The scale dimensions are as follows: skill variety, task identity, task significance, autonomy, feedback from the job itself, feedback from agents, and dealing with others. For each dimension a mean of the responses belonging to that dimension was calculated. The questions were divided into two subsections. In the first section, respondents indicated the amount of each characteristic in the job on a scale from 1 to 7 . In the second section, they rated the accuracy of statements describing the job. The higher the score on each dimension, the more the characteristic was present in the job.

For each participant a motivating potential score (MPS) was calculated. To do this, the mean item ratings for skill variety, task identity, and task significance were summed. This quantity was divided by three, after which the quantity was multiplied first by the autonomy rating and then by the feedback from job rating. Hackman and Oldham state that internal reliability coefficients range between .68 and .72 and that this low range has often been attributed to educational differences among subjects.

Three versions of this scale were also used. Participants used the JRF and incumbents completed the JDS. These forms differed only in the wording, otherwise the content was identical. For instance, the JRF for participants (or 
applicants) asked for ratings of the dispatch job, while the JDS for dispatcher incumbents asked for ratings of their job. The third version for participants' ideal job ratings asked for ratings of their ideal job.

Organizational Culture Profile (Appendix D, pages 69-70), Organizational climate was measured by the Organizational Culture Profile (OCP) developed by O'Reilly, Chatman, and Caldwell (1991). The OCP was developed using a Q-sort procedure, but the response scale was converted to a five-point Likert scale for this study. It contained 54 organizational values or characteristics.

Respondents indicated how accurately each characteristic described the organization in question. A high score indicated that the value was very characteristic of the organization, while a low score indicated the value was less descriptive or less accurate of the organization. Again three versions were used, with the only difference appearing in the instructions. Participants were asked to decide how characteristic each item was of their ideal organization and also of WCCCA. Incumbents were asked to rate the degree to which each item characterized WCCCA.

Chatman (1991) found eight factors arising from the OCP. These factors are: innovation and risk taking, attention to detail, orientation toward outcomes, aggressiveness and competitiveness, supportiveness, emphasis on rewards, team 
orientation, and decisiveness. Each factor is comprised of 3-8 items on the questionnaire. A mean item rating was found for each factor. Previous research has found the test-retest reliability of the measure to range from $.65-.87$ (Chatman, 1991).

\section{Self-Selection (Appendix E)}

Self-selection was measured with five self report items based on an expansion of previous self-selection measures and expected utility. The questionnaire contained the following questions:

1. Given your ideal job, how likely is it that this job will match your ideal?

2. What do you think is the likelihood that you will be extended an offer of employment for this job?

3. What is the likelihood that you will stay in this position for 2 years?

4. How likely is it that you will return for continued testing if you are called to come back?

5. What is the likelihood that you will accept a job offer?

Respondents were asked to rate the probability of their actions on a five-point Likert scale, with the anchors absolutely will not and absolutely will. Participants were asked the questions immediately following the research session and approximately a week later when they received the questionnaire in the mail. A high score indicated that the respondent was self-selecting into the job, while a low score indicated self-selection out of the job. Coefficient alphas were calculated from the immediate data and from the mailed responses. For the 
immediate response data the alpha $=.496$, while the alpha $=.676$ for the mailed data. In both cases question two was deleted due to an increase in the alpha coefficient (.615 time $1, .776$ time 2$)$.

Due to the exploratory nature of the self-selection construct, applicants were asked three additional questions regarding the role of several factors which potentially could influence the self-selection decision. The results of these questions were not used in the analyses, although the results were discussed in terms of future research. Two questions were quantitative and asked to what degree did the RJP or the testing influence their interest in the job. The third question was open-ended and asked the applicant to list any other factors which had influenced their interest in the job.

Realistic Job Preview. The RJP was a 12 minute videotape. Five incumbents, representative of the racial and gender composite of the agency, were selected by the director of the agency to develop the videotape. These incumbents presented information about the three dimensions of the job profile measure (job tasks, job characteristics, and organizational climate). The job analysis provided general job topics that were focused on in the RJP. However, subject matter experts or dispatch incumbents also met to discuss the question: what aspects of the dispatch job would surprise or cause problems for new trainees? The ideas 
that were generated during this meeting were incorporated with the job analysis data and classified into three content areas (tasks, characteristics, and organization).

All incumbents who participated in the development of this video were compensated for their time by the agency and the taping was completed by the Portland State TV Services Department. Taping the RJP was done in two ways. The first involved utilizing peer dyads where one incumbent spoke to another incumbent sitting directly next to the camera. This method allowed for greater conversational style than reading from a script would have because the peer is a familiar face who provides non-verbal feedback (J. G. Kimball, personal communication, January 23,1995 ). The second format involved the taping of the incumbents engaged in a group discussion.

\section{Brocedure}

As seen in table 1, two steps in the procedure were completed prior to data collection: the dispatch incumbents completed the Job Profile Measure and the RJP was produced.

Data collection involved four phases. During the first phase participants were asked to read and complete an informed consent statement which emphasized the confidentiality of their participation and the independence of the 
study and hiring process (see Appendix F). At this time participants were assigned a subject number to maintain confidentiality. All data were linked through this number and names were only used for mailing purposes.

During the second phase participants completed the Job Profile Measure twice, once for their ideal job and once for their expectations of the dispatch job. After these were completed, participants moved to another room and began the testing for the job. The testing consisted of a multiple choice test and a forced choice self-description test. Both of these tests were administered independently from the researcher.

During the third phase, the participants returned to the research room and viewed the RJP. They then completed the Job Profile Measure for the third time. This version of the measure again asked for their expectations of the dispatch job. Participants were then dismissed. Participants also completed the self-selection measure and demographic questionnaire during this phase.

The fourth phase was completed via mail. Approximately two days after the testing session, participants received the self-selection measure again and a postage paid return envelope. The self-selection measure was completed twice to ensure a high response rate. They were asked to return this questionnaire within three days. A $65 \%$ response rate was obtained. 


\section{Table 1}

\begin{tabular}{|c|c|c|c|}
\hline $\begin{array}{l}\text { PHASE } \\
\end{array}$ & TIME & DESCRIPTION & MEASURES \\
\hline $\begin{array}{l}\text { Pre-data } \\
\text { Collection }\end{array}$ & $\begin{array}{l}3 \\
\text { hours } \\
15 \mathrm{~min}\end{array}$ & $\begin{array}{l}\text { RJP Developed } \\
\text { Incumbents rated dispatch job }\end{array}$ & $\begin{array}{l}\text { Job Profile Measure: } \\
\text { - Job Task Scale } \\
\text { - Organarizational Climate Scale }\end{array}$ \\
\hline ONE & $5 \min$ & & Informed Consent \\
\hline TWO & $\begin{array}{l}15 \min \\
15 \min \\
1 \text { hour }\end{array}$ & $\begin{array}{l}\text { Participants rated ideal job } \\
\text { Participants rated expectations } \\
\text { of dispatch job } \\
\text { Participants completed Job } \\
\text { Testing }\end{array}$ & $\begin{array}{l}\text { Job Profile Measure: } \\
\text { - Job Task Scale } \\
\text { - Job Characteristics Scale } \\
\text { Organizational Climate Scale } \\
\text { Muttiple Choice \& Forced Choice }\end{array}$ \\
\hline THREE & $15 \mathrm{~min}$ & $\begin{array}{l}\text { Participants viewed RJP } \\
\text { Participants rated expectations } \\
\text { of dispatch job }\end{array}$ & $\begin{array}{l}\text { RJP } \\
\text { Job Profile Measure: } \\
\text { - Job Task Scale } \\
\text { - Job Characteristics Scale } \\
\text { Self-Selection Measure }\end{array}$ \\
\hline FOUR & $5 \mathrm{~min}$ & $\begin{array}{l}\text { Participants received follow-up } \\
\text { questionnaire after research } \\
\text { session. It was to be returned } \\
\text { in three days }\end{array}$ & Self -Selection Measure \\
\hline
\end{tabular}




\section{Results}

\section{Hypothesis 1}

\section{Job Tasks \& Characteristics}

Due to the small sample size, paired sample t-tests were used to test hypothesis 1 , the difference between pre-RJP ratings and post-RJP ratings. Specifically, t-tests were utilized to analyze pre and post RJP task ratings (both non-distractor and distractor items) and pre and post job characteristic ratings (MPS Score). Table 2 shows the non-significant results for each of these variables. The RJP had no significant affect on applicants' ratings of the job tasks or job characteristics.

\section{Table 2:}

T-test Results

\begin{tabular}{|l|c|c|c|}
\hline & t-Value & df & Significance Level \\
\hline Non-distractor Task Items & -1.02 & 23 & 0.319 \\
\hline Distractor Task Items & -0.69 & 23 & 0.498 \\
\hline MPS Score & 0.49 & 22 & 0.631 \\
\hline
\end{tabular}

However, to further explore the variable which should have been most influenced by the RJP, a chi-square analysis was done on the job task ratings. Four variables were created to complete the analysis: distractor items pre-RJP, distractor items post-RJP, non-distractor items pre-RJP, non-distractor items postRJP. To compute these variables, each applicant's mean task rating was found for 
the non-distractor items and the distractor items. This mean was then compared to the incumbent grand mean of those items. Then, the standard deviation of the incumbent means was calculated. If the applicant mean rating was within one standard deviation of the incumbent grand mean, the participant was considered in agreement with the incumbent and their case was coded a "1". If the applicant rating was greater than one standard deviation from the incumbent grand mean, there was no agreement and the case was coded a " 0 ".

\section{Table 3:}

CHI-SQUARE

RESULTS

\begin{tabular}{|c|c|c|c|c|c|c|c|c|}
\hline Variable & $\begin{array}{c}\text { No. } \\
\text { Cases } \\
\text { "1" } \\
\text { Agree }\end{array}$ & $\begin{array}{c}\text { No. } \\
\text { Cases } \\
\text { "0" Non- } \\
\text { Agree } \\
\end{array}$ & Mean & SD & Cases & Mean & SD & Cases \\
\hline 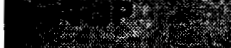 & & & & & & & & \\
\hline Non-distractors & 12 & 13 & 4.765 & 0.223 & 40 & 4.900 & 0.122 & 25 \\
\hline Distractors & 7 & 19 & 4.035 & 0.505 & 40 & 4.536 & 0.461 & 24 \\
\hline 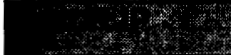 & & & & & & & & \\
\hline Non-distractors & 8 & 16 & & & & 4.930 & 0.130 & 24 \\
\hline Distractors & 15 & 9 & & & & 4.388 & 0.479 & 24 \\
\hline
\end{tabular}

The chi-square results were in the predicted direction and significant for only the pre-RJP distractor items $\left(\chi^{2}(1, \mathrm{~N}=24)=5.539, \mathrm{p}=.0186\right)$. This indicates that there was a significant difference in agreement frequency for the distractor items before the RJP. As seen in table 3,19 of the 26 observed cases 
were coded a "0" for non-agreement. This is compared to the post-RJP distractor items in which the chi-square results were non-significant $\left(\chi^{2}(1, \mathrm{~N}=24)=1.500\right.$, $p=.2207)$ and in which 15 of the 24 observed cases were coded a " 1 " for agreement. It appears that there was some movement towards agreement between the applicants and incumbents on the task distractor ratings after viewing the RJP. There was no such movement for the non-distractor items. Instead, there was a slight movement towards non-agreement. The chi-square was not significant pre- $R J P\left(\chi^{2}(1, N=25)=.0400, p=.8415\right)$. This means that there was not a significant difference in frequency of agreement. Again seen in table 3, only 12 of the 25 observed cases were considered in agreement. The results were also not significant post-RJP $\left(\chi^{2}(1, N=24)=2.667, p=.1025\right)$. However, now only 8 of the 24 cases were in agreement. This indicates that there was a slight movement towards non-agreement. A review of the means in table 3 illustrates these results. For instance, applicant ratings (non-distractor and distractor) are higher than incumbent ratings both before and after the RJP. However, after the RJP the applicant mean distractor rating decreased (moved closer to incumbent) but the mean non-distractor rating increased (moved away from incumbent). 


\section{Organizational Culture}

To test the differences between pre-RJP and post-RJP responses on the OCP, applicant ratings and incumbent ratings were correlated for the eight OCP factors (see Appendix G). There was a significant correlation (at the .10 level) for the supportiveness factor pre-RJP $(r=-.3862, p=.057)$. This negative correlation indicates that applicants and incumbents did not rate the organization in the same way prior to the RJP. This correlation, however, was still negative and not significant post- $R J P(r=-.3398, p=.104)$. The hypothesis suggests that while the ratings should be significantly negatively correlated pre-RJP, they should be positively correlated post-RJP. These results do not support the hypothesis that the applicant ratings were influenced by the RJP.

Applicant and incumbent ratings on the attention to detail $(r=-.4309$, $\mathrm{p}=.036)$ and decisiveness $(\mathrm{r}=-.3705, \mathrm{p}=.075)$ factors were significantly correlated (at the .10 level) post RJP. The correlations were, however, not significant pre-RJP. These results are again counter in direction to the expected correlations. The results indicate that applicant and incumbent ratings of the organization were significantly different after the RJP on these factors, but not before. Considering all of these analyses, hypothesis 1 cannot be confirmed. 


\section{Hypothesis 2 \& Hypothesis 3}

Two MANOVAs were used to test hypotheses 2 and 3, the convergence of applicant expectations with incumbents. The first analysis tested the difference between applicant's pre-RJP expectations and incumbent ratings. The second analysis tested the difference between applicant's post-RJP expectations and incumbent ratings. In these analyses, the RJP level was considered to be a categorical variable with two levels, applicant and incumbent. The dependent variables consisted of three summary scores calculated from the Job Profile Measure. These were considered to be continuous. The first summary score was the mean of the 10 distractor items from the Job Tasks Scale (Task Score). The second summary score was the MPS score calculated from the Job Characteristics scale (MPS). The third summary score was the overall mean of the eight factors found in the OCP scale (Organizational score). For the incumbents, the summary scores were calculated as the grand mean of the individual summary scores.

Table 4 describes the results of the MANOVAs. For the pre-RJP data the wilks' lambda was significant at $p=.000$. This indicates that before viewing the RJP applicants and incumbents rated the job differently. The squared canonical correlation indicates that $48 \%$ of the variance in the job ratings was accounted for by the designation of respondent as applicant or incumbent. The standardized 
discriminant function coefficients are presented in table 5 . These indicate that the variable contributing most to the difference between incumbents and applicants was the organizational score (-740). However, the MPS score (-.365) and the Task score $(-.310)$ were also important variables to consider.

\section{Table 4}

MANOVA: Tests of

Significance

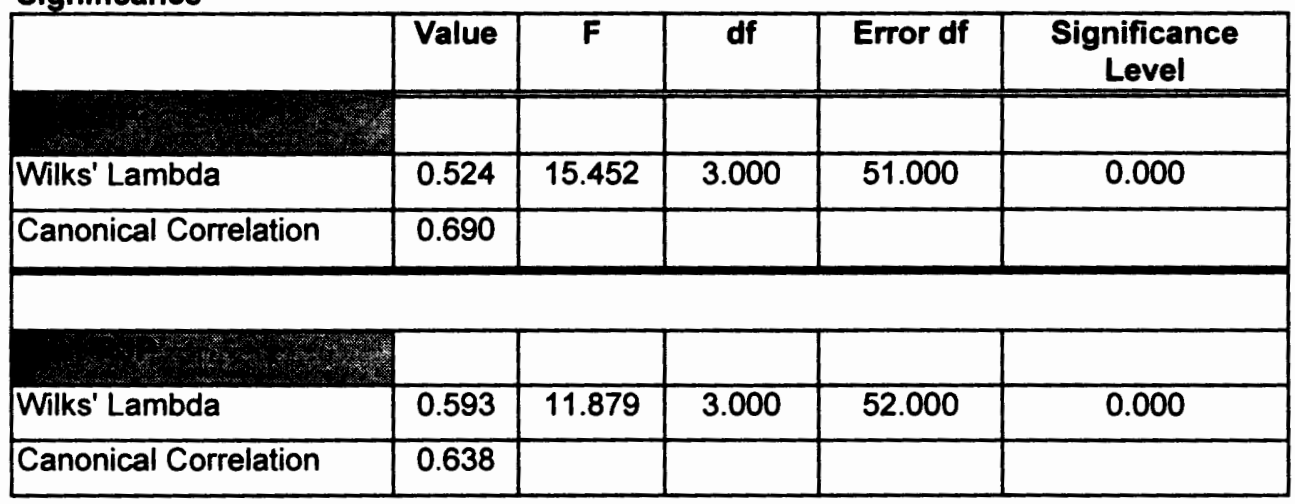

For the post-RJP data, the wilks' lambda was also significant at $\mathrm{p}=.000$. These results are similar to the pre-RJP data. Slightly less variance in job ratings, $41 \%$, was accounted for by membership in one of these two groups. Reported in table 5 are the standardized discriminant function coefficients for this MANOVA. Again, the organizational score was the greatest contributor to the differences found (-.798). While applicants and incumbents rated the job significantly different both before and after the RJP, the task score ( -.310 vs. -.234$)$ played a less important role in the group difference after the RJP. The MPS score $(-.365$ 
vs. -.319) was also somewhat less important, but the organizational score was

more important (-.740 vs. -.798$)$.

Table 5

MANOVA: Standardized Discriminant

Function

Coefficients \& Descriptive

Statistics

\begin{tabular}{|c|c|c|c|c|c|c|c|}
\hline Variable & $\begin{array}{c}\text { Std. } \\
\text { Coeff. }\end{array}$ & Mean & SD & Cases & Mean & SD & Cases \\
\hline \multicolumn{8}{|l|}{ Pre-RJP } \\
\hline MPS Score Pre-RJP & -0.365 & 97.655 & 36.300 & 38 & 147.712 & 51.507 & 25 \\
\hline $\begin{array}{l}\text { Organizational Score } \\
\text { Pre-RJP }\end{array}$ & -0.740 & 3.123 & 0.351 & 33 & 3.600 & 0.220 & 24 \\
\hline Task Score Pre-RJP & -0.310 & 4.035 & 0.505 & 40 & 4.536 & 0.461 & 25 \\
\hline \multicolumn{8}{|l|}{ Post-RJP } \\
\hline $\begin{array}{l}\text { MPS Score Post- } \\
\text { RJP }\end{array}$ & -0.319 & & & & 146.142 & 62.486 & 24 \\
\hline $\begin{array}{l}\text { Organizational Score } \\
\text { Post-RJP }\end{array}$ & -0.798 & & & & 3.561 & 0.207 & 24 \\
\hline Task Score Post-RJP & -0.234 & & & & 4.388 & 0.479 & 24 \\
\hline
\end{tabular}

A review of the means by group shown in table 5 indicates that the overall difference between applicants and incumbents occurs because applicants provided higher summary score ratings than the incumbents. This occurred in both the preRJP data and in the post-RJP data.

Although hypotheses 2 and 3 cannot be confirmed, it seems reasonable that of the three job profile components, the task score was the source of the least difference between applicants and incumbents. This is because the RJP focused 
on task information. In addition, the chi-square results noted earlier indicated that there was not a significant difference between applicant and incumbent task ratings post-RJP.

\section{Hypothesis 4}

Three steps were completed to test hypothesis 4 . First, three summary scores were calculated from the applicants' ideal job ratings. These were exactly the same as the summary scores used in the previous analysis (task score, MPS, organizational score) except that:

a.) they were calculated using applicants' ideal job ratings instead of their expectation ratings of the dispatch job and

b.) the task score was the mean of the 10 non-distractor items instead of the distractor items.

Secondly, fit scores were calculated. These provided a measure of the difference between the applicants' ideal job ratings and incumbents' actual job ratings. The fit score was the absolute value of the difference between each applicant's summary score and the grand mean of the incumbents' summary scores. The less difference found in these ratings, the greater the fit score.

The third step in this analysis involved correlating the three fit scores with the mean of the self-selection ratings. Self-selection measures were obtained at 
two different times, immediately following the RJP and a week later. Means of both measures were used in this analysis.

As noted in table 6, there were no significant correlations. This finding may be due to the extremely small sample sizes, particularly at time 2 . However, all correlations were in the expected direction. The negative correlations indicate that as the fit score increased (i.e. more difference/worse fit), the self-selection rating decreased. A decrease in the self-selection rating means that the applicant was tending to select out of the hiring process. It should also be noted that the correlations tended to be stronger at time 2 than at time 1 . In addition, the means of the self-selection ratings were similar between time $1(\mathrm{M}=4.61, \mathrm{SD}=.35)$ and time $2(\mathrm{M}=4.51, \mathrm{SD}=.45)$. This suggests consistency within the ratings but a slightly stronger tendency for applicants to self-select out at time 2 .

\section{Table 6}

Correlation Coefficients:

Self-Selection

\begin{tabular}{|l|c|c|}
\hline & SS (Time1) & SS (Time 2) \\
\hline & $r=-0.359$ & $r=-0.4026$ \\
& $P=.085$ & $P=.109$ \\
& $N=24$ & $N=17$ \\
\hline & $F=-0.018$ & $r=-0.209$ \\
& $P=.933$ & $P=.419$ \\
& $N=24$ & $N=17$ \\
\hline & $r=-0.142$ & $F=-0.393$ \\
& $P=.529$ & $P=.132$ \\
& $N=22$ & $N=16$ \\
\hline
\end{tabular}


It is interesting to note that the strongest correlations were found for the task fit scores. Therefore, even though the task score accounted for the least amount of variance between applicants and incumbents, it seems to be the best predictor of self-selection. Although hypothesis 4 cannot be accepted from these data, the trends do appear in the expected direction.

The exploratory questions from the self-selection measure yielded the following results. The greatest number of participants (38\%) indicated that the RJP had "very much" influenced their interest in the dispatcher job. Only $21 \%$ indicated that it had "not at all" or "very little" influenced their interest. Combining the middle categories, resulted in $42 \%$ of the respondents indicating that the RJP "moderately" or "somewhat" influenced them.

The testing, however, did not have the same effect. A total of $44 \%$ of the participants said that the testing influenced their interest in the job "not at all" or "very little". Twenty percent indicated a "moderate" degree of influence while $36 \%$ indicated "some" or "very much" influence.

The open-ended responses to the question "what other factors have influenced your interest in dispatch," focused on the desire to help others. The 
second most frequently mentioned reason was previous experience in dispatch, law enforcement, EMS, or fire. Rescue 911 was also indicated once, as was pay.

\section{Discussion}

The results of this study did not support the proposed hypotheses.

Nonetheless, the data in most cases, were in the expected direction. These trends and their implications are discussed.

Although past literature has confirmed the effectiveness of RJPs in altering applicants' initial job expectations, the present study does not support this finding. Instead, the results indicated that the RJP only increased the agreement between applicant and incumbent job task ratings. However, this result only occurred for the task distractor items and not for the task non-distractor items. At first glance, the lack of significant difference between the applicants and incumbents on task ratings seems to support the conclusion found by Smith and Hakel (1979). They argued that even with little information, naive job raters could rate job tasks as well as job incumbents. However, the difference in distractor and non-distractor findings does not support this view. If, in fact, applicants and incumbents shared dispatcher job stereotypes (as proposed by Harvey \& Lozada-Larsen, 1988) applicants would have rated distractor items as well as incumbents both before and after receiving RJP information. However, 
this result was not found. Instead, applicants were as accurate as incumbents when rating the major dimensions of the job, (non-distractors) but less accurate on the finer distinctions of the job (denoted in the distractor items). It seems that the more information is provided to the naive rater (applicant) the greater their rating accuracy. The conclusion is that the "amount of job descriptive information available to raters had a significant effect on job analysis accuracy “ (Harvey \& Lozada-Larsen, p. 460) and that the RJP enhanced the applicants' ability to discriminate between accurate and false task information.

The results also did not indicate that any of the applicants' job ratings became more similar to the incumbents' ratings after viewing the RJP. Nonetheless, the results did indicate that the RJP provided the most information about job tasks and the least information about the organization. For instance, before the RJP the applicant and incumbent ratings differed on all three dimensions; job tasks, job characteristics, and organizational climate. After the RJP, however, the difference due to organizational ratings increased but that due to job task ratings decreased.

The most encouraging finding in this study was found in the self-selection data. Again, the results were not significant, but they were in the expected direction. As the fit between an applicant's ideal job ratings and the dispatch job 
ratings decreased, their propensity to self-select out of the hiring process increased. It appears that applicants do compare the information obtained from a RJP to their ideal job requirements and translate that comparison into ideas about continuing with the hiring process. This is an important result because this study attempted to measure self-selection in a new way. However, more research on self-selection needs to be done. The assumption inherent in the analyses of this study is that the responses were on an interval scale. The non-significant results may have been due to the measure being an ordinal scale instead. This means that the ratings obtained may have only provided a relative ranking of self-selection attitudes, and not a measure of magnitude.

The most obvious limitation of this study, and perhaps the most reasonable explanation of why even results replicating previous studies did not turn out as expected, is an entirely too small sample. In fact, Cohen's power tables (Cohen \& Cohen, 1983) indicate that the t-test results for hypothesis 1 only had a power level of .33. This power level is based on the mean effect size cited by Premack and Wanous (1985) for change in employment expectations of -.34, a sample size of 26 , and an alpha level of .05 . This means that there was only a $33 \%$ probability of finding a significant result given these parameters. Likewise, the correlations for self-selection (hypothesis 4 ) had a power level of only .08 , based on the effect 
size of $.12, N=26$, and $p=.05$. Obtaining an adequate power level of .80 would have required a sample size of 84 to test the expectation hypothesis and a sample of 783 to test the self-selection hypothesis. Obviously, the sample size used in this study could not adequately test the hypotheses. However, the trends in the data suggest that with a larger sample, job task results would have been significant.

Another limitation of this study is that the RJP was limited in content. Even though it was intended to provide a complete job profile, the incumbents found it particularly difficult to discuss organizational characteristics in a politically sensitive manner. Therefore, the RJP was particularly strong in information about the job tasks and much weaker in information about the organization. This would surely explain why the results regarding the OCP were not significant.

Several possible confounds exist in this study. For instance, self-selection ratings were expected to be significantly influenced by the length of time applicants had been looking for a job. Although it was impossible to empirically assess the effect of this information on self-selection, more than $50 \%$ of the respondents had only been looking for a job $0-3$ months. Therefore, this would not have been expected to be a significant moderating variable. It was also 
anticipated that participation in a community dispatch educational program would influence self-selection. Again, it was impossible to empirically assess this variable, but it would have only been relevant to $20 \%$ of the applicants. In fact, it is the author's assessment that being a dispatch student was particularly influential in the applicant's decision to participate in the study. For instance, it seemed that applicants who were students in such a program chose not to participate in this study. This was presumably because they did not perceive the need to learn more about the dispatch job. This "self-selection of participants" may have confounded the results. Those that decided not to participate may have had the most misconceptions about the job but perceived that they were accurately informed. Conceivably, therefore, these applicants' expectations would have been most challenged by the RJP. Furthermore the change in their expectations may have then translated into a definitive self-selection decision.

The testing may have also confounded the results. The tests were based entirely on the same job analysis which provided information for the RJP. These tests were also perceived to be extremely face valid by the test constructors. Therefore, the post-RJP ratings must be interpreted as post-testing also. It is, therefore, unclear if the results were due to the RJP or the test. Having said this, the exploratory self-selection questions did provide some evidence that applicants 
were more influenced by the RJP than the testing. Nonetheless, more research needs to be conducted to sort out this confound.

The overwhelming conclusion is that more research needs to be conducted with an adequate sample size. Regardless of the lack of statistical significance, it is still argued that content validity is important in RJP research. Content validity is the only way to ensure that the RJP accurately reflects the job in question. This is particularly important in assessing the complicated relationship between the RJP, fit, and self-selection. It is also suggested that future studies utilize a measure of self-selection based on expectancy theory. The correlational trends in the data support the expectancy theory hypothesis. Future research should also examine the relationship between pre-employment testing and self-selection. Research has suggested that recruitment procedures, such as the RJP, may actually eliminate the most qualified applicants (Boudreau \& Rynes, 1985). Murphy, (1986) has further suggested that if the top performers reject employment offers there is a loss of utility in selection tests. This would imply that the utility of the RJP would be reduced. Nonetheless, the utility of preemployment self-selection cannot be underestimated. When the job is not instrumental in achieving valued goals for the applicant (i.e. no fit), postemployment self-selection is likely to occur. Therefore, although it is important 
to understand the relationship between RJPs and qualifications of applicants, it is not suggested that the use of a RJP be limited. Post-entry self-selection is unequivocally more costly than pre-entry self-selection. Understanding more about the role of expectancy theory in self-selection would, however, be the first step in understanding this relationship. It would also lead to a more joint and equitable decision process. 


\section{References}

Boudreau, J. W. \& Rynes, S. L. (1985). Role of recruitment in staffing utility analysis. Journal of Applied Psychology, 70, 354-366.

Breaugh, J. A. (1983). Realistic job previews: A critical appraisal and future research directions. Academy of Management Review, 8, 612-619.

Burke, R. J., \& Deszca, G. (1988). Career orientations, satisfaction and health among police officers: Some consequences of person-job misfit. Psychological Reports, 62, 639-649.

Chatman, J. A. (1991). Matching people and organizations: Selection and socialization in public accounting firms. Administrative Science Quarterly, 36, 459-484.

Cherniss, C. (1980). Professional burnout in human service organizations. New York: Praeger.

Cohen, J. \& Cohen, P. (1983). Applied multiple regression/correlation analysis for the behavioral sciences. Hillsdale, NJ: Lawrence Erlbaum Assoc.

Colarelli, S. M. (1984). Methods of communication and mediating processes in realistic job previews. Journal of Applied Psychology, 69, 633-642.

Gaugler, B. B. \& Thornton, G. C. (1990). Matching job previews to individual applicants' needs. Psychological Reports, 66, 643-652. 
The Effects of a RJP 54

Hackman, J. R., \& Oldham, G. R. (1980). Work Redesign. Reading, MA: Addison-Wesley.

Harvey, R. J. \& Lozada-Larsen, S. R. (1988). Influence of amount of job descriptive information on job analysis accuracy. Journal of Applied Psychology, 73, 457-461.

Holland, J. L. (1985). Making vocational choices. Englewood Cliffs, NJ: Prentice-Hall.

Kahneman, D., \& Tversky, A. (1979). Prospect theory: An analysis of decision under risk. Econometrica, 47, 263-291.

Landy, F. J., Shankster, L. J., \& Kohler, S. S. (1994). Personnel selection and placement. Annual Review of Psychology, 45, 261-296.

Lichtenberg, J. W., Shaffer, M., \& Arachtingi, B. M. (1993). Expected utility and sequential elimination models of career decision making. Journal of Vocational Behavior, 42, 237-252.

Murphy, K. R. (1986). When your top choice turns you down: Effect of rejected offers on the utility of selection tests. Psychological Bulletin. 99, 133138. 
Myers, I. B., \& McCaulley, M. H. (1985). Manual: A guide to the development and use of the Myers-Briggs Indicator. Palo Alto, CA: Consulting Psychologists Press.

Offerman, L. R., \& Gowing, M. K. (1993). Personnel selection in the future: The impact of changing demographics and the nature of work. In N. Schmitt, W. C. Borman \& Associates (Eds.), Personnel selection in organizations (pp. 385-417). San Francisco, CA: Jossey-Bass.

O'Reilly, C. A., Chatman, J. A., \& Caldwell, D. F. (1991). People and organizational culture: A profile comparison approach to assessing personorganization fit. Academy of Management Journal, 34, 487-516.

Posner, B. Z. (1981). Comparing recruiter, student, and faculty perceptions of important applicant and job characteristics. Personnel Psychology, 34, 329-339.

Premack, S. L., \& Wanous, J. P. (1985). A meta-analysis of realistic job preview experiments. Journal of Applied Psychology, 70, 706-719.

Primoff, E. (1975). How to prepare and conduct job element examinations. Washington, DC: U.S. Government Printing Office. (NTIS No. TS-75-1). 
Reilly, R. R., Brown, B., Blood, M. R., \& Malatesta, C. Z. (1981). The effects of realistic previews: A study and discussion of the literature. Personnel Psychology, 34, 823-834.

Rynes, S. L. (1993a) . When recruitment fails to attract: Individual expectations meet organizational realities in recruitment. In H. Schuler, J. L. Farr, \& M. Smith (Eds.), Personnel selection and assessment: Individual and organizational perspectives (pp. 27-40). Hillsdale, NJ: Lawrence Erlbaum Associates.

Rynes, S. L. (1993b). Who's selecting whom? Effects of selection practices on applicant attitudes and behavior. In N. Schmitt, W. C. Borman \& Associates (Eds.), Personnel selection in organizations (pp. 240-274). San Francisco: Jossey-Bass.

Saks, A. M., \& Cronshaw, S. F. (1990). A process investigation of realistic job previews: Mediating variables and channels of communication. Journal of Organizational Behavior, 11, 221-236.

Schuler, H. (1989). Some advantages and problems of job analysis. In M. Smith \& I. Robertson (Eds.), Advances in selection and assessment (pp. 31-42). Chichester, NY: John Wiley \& Sons. 
Schuler, H., Farr, J. L., \& Smith, M. (Eds.). (1993). Personnel selection and assessment: Individual and organizational perspectives. Hillsdale, NJ: Lawrence Erlbaum Associates.

Smith, J. E. \& Hakel, M. D. (1979). Convergence among data sources, response bias, and reliability and validity of a structured job analysis questionnaire. Personnel Psychology, 32, 677-692.

Super, D. (1957). The psychology of careers. New York: Harper \& Row.

Suszko, M. K., \& Breaugh, J. L. (1986). The effects of realistic job previews on applicant self-selection and employee turnover, satisfaction, and coping ability. Journal of Management, 12, 513-523.

Trost, G., \& Kirchenkamp, T. (1993). Predictive validity of cognitive and noncognitive variables with respect to choice of occupation and job success. In H. Schuler, J. L. Farr, \& M. Smith (Eds.), Personnel selection and assessment: Individual and organizational perspectives (pp. 303-314). Hillsdale, NJ: Lawrence Erlbaum Associates.

Vroom, V. H. (1966). Organization choice: A study of pre and postdecision processes. Organizational Behavior and Human Performance, 1 . 212-225. 
Wanous, J. P. (1973). Effects of a realistic job preview on job acceptance, job attitudes, and job survival. Journal of Applied Psychology, 58, 327-332.

Wanous, J. P. (1980). Organizational entry: Recruitment, selection and socialization of newcomers. Reading, MA: Addison-Wesley.

Wilensky, H. L. (1956). Intellectuals in labor unions:-Organizational pressures on professional roles. Glencoe, IL: Free Press. 
The Effects of a RJP 59

APPENDIX A

JOB ELEMENT RATING BLANK 


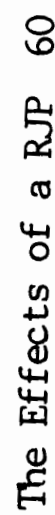

JOB ELEMENT BLANK

Rater Name:

Title and Agency:

\begin{tabular}{|c|c|c|c|c|c|c|c|c|c|c|c|c|c|}
\hline Element & 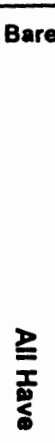 & 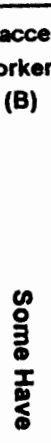 & 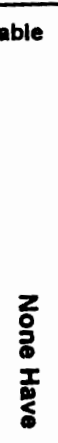 & 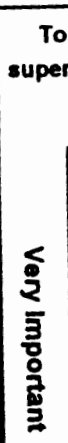 & $\begin{array}{l}\text { pick } \\
\text { or wo } \\
\text { (S) }\end{array}$ & 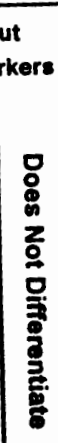 & 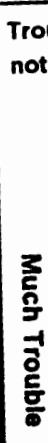 & $\begin{array}{l}\text { ible } \\
\text { cons } \\
\text { (T }\end{array}$ & 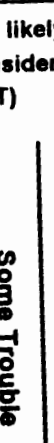 & 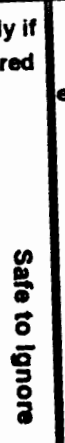 & $\begin{array}{r}\mathrm{Pr} \\
\text { Dema } \\
\text { elemen }\end{array}$ & 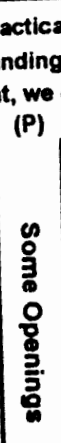 & 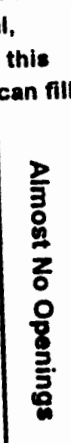 \\
\hline & 2 & 1 & 0 & 2 & 1 & 0 & 2 & & 1 & 0 & 2 & 1 & 0 \\
\hline & 2 & 1 & 0 & 2 & 1 & 0 & 2 & & 1 & 0 & 2 & 1 & 0 \\
\hline & 2 & 1 & 0 & 2 & 1 & 0 & 2 & & 1 & 0 & 2 & 1 & o \\
\hline & 2 & 1 & 0 & 2 & 1 & 0 & 2 & & 1 & 0 & 2 & 1 & 0 \\
\hline & 2 & 1 & 0 & 2 & 1 & 0 & 2 & & 1 & 0 & 2 & 1 & 0 \\
\hline & 2 & 1 & 0 & 2 & 1 & 0 & 2 & & 1 & 0 & 2 & 1 & 0 \\
\hline & 2 & 1 & 0 & 2 & 1 & 0 & 2 & & 1 & 0 & 2 & 1 & 0 \\
\hline & 2 & 1 & 0 & 2 & 1 & 0 & 2 & & 1 & 0 & 2 & 1 & 0 \\
\hline & 2 & 1 & 0 & 2 & 1 & 0 & 2 & & 1 & 0 & 2 & 1 & 0 \\
\hline & 2 & 1 & 0 & 2 & 1 & 0 & 2 & & 1 & 0 & 2 & 1 & 0 \\
\hline & 2 & 1 & 0 & 2 & 1 & 0 & 2 & & 1 & 0 & 2 & 1 & 0 \\
\hline & 2 & 1 & 0 & 2 & 1 & $\underline{0}$ & & & 1 & 0 & 2 & 1 & 0 \\
\hline & 2 & 1 & 0 & 2 & 1 & 0 & & & 1 & 0 & 2 & 1 & 0 \\
\hline & 2 & 1 & 0 & 2 & 1 & $\underline{0}$ & & 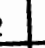 & 1 & 0 & 2 & 1 & 0 \\
\hline & 2 & 1 & 0 & 2 & 1 & 0 & & 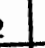 & 1 & 0 & 2 & 1 & 0 \\
\hline & 2 & 1 & o. & 2 & 1 & 0 & & & 1 & 0 & 2 & 1 & 0 \\
\hline & 2 & 1 & 0 & 2 & 1 & 0 & & 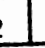 & 1 & 0 & 2 & 1 & 0 \\
\hline
\end{tabular}


The Effects of a RJP 61

APPENDIX B

LETTER TO PARTICIPANTS 
February, 1995

\section{Dear Applicant:}

I am a graduate student doing research on job applicants and the expectations they have about the job they are applying for. I will be conducting my research at Washington County Consolidated Communications Agency during the time of testing for the Dispatcher I position.

I would like to ask for your participation in my study. It will require that you complete several questionnaires asking you to describe your expectations of the job and your ideal job. You will also have the opportunity to view a videotape of current dispatchers talking about the dispatcher job.

Please be assured that all of your responses will be completely confidential. Your name will only be used for the purpose of sending you a short follow-up questionnaire in the mail. All other questionnaires will be completed with a arbitrary subject number. NO member of WCCCA will see your responses and your participation in this study is completely voluntary. It will in no way influence your chances of being hired or your relationship with WCCCA.

I would encourage you to participate in this study if at all possible because it is a unique opportunity for you to learn more about the dispatcher job from the point of view of current dispatchers. It will also help increase our knowledge of applicants in the selection process.

If you are willing to participate, please arrive at Washington County at $x: x x p . m$. February, 1995. You will be asked to complete several questionnaires before the testing and several after the testing. Your entire participation will involve approximately 1 hour.

If you have any questions, please contact WCCCA at $x x x-x x x x$ and leave a message, I will retum your call promptly.

Thank you for your help, 
The Effects of a RJP 63

APPENDIX C

DEMOGRAPHIC QUESTIONNAIRE 


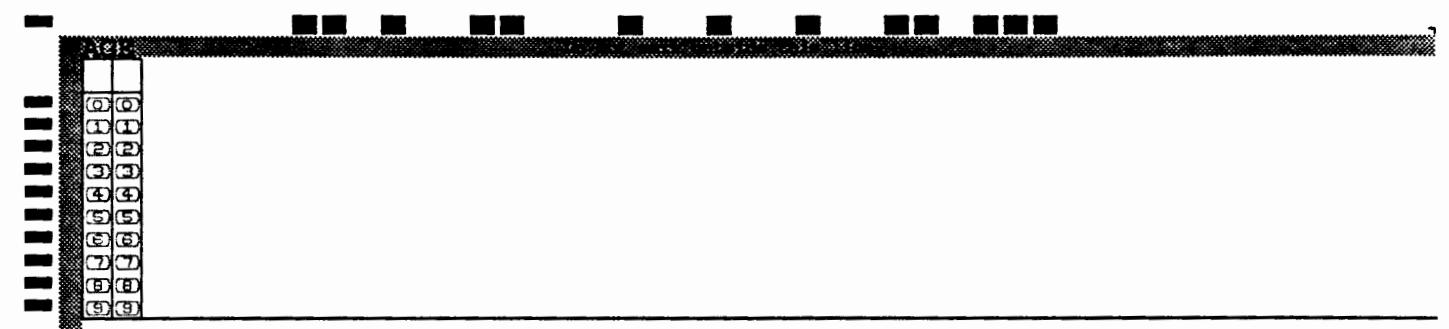

Describe here othex thinge that have influenced your latereat in the fob of dippatcher.

What is your gender? Qmale $\square$ remale

Please enter your age in the boxes above, and fill in the corresponding bubbles.

Bducational level: $\square$ some Algh school

$\square$ High school diplom

$\square$ som Bunimes college or technieal echool experience

$\square$ som college experience (other than bueiness or technical echool)

$\square$ pusiness college or technical school degree

$\square$ college Degree

$\checkmark$ Martex's or highex degree

How long have you boen MCTIVzeY looking for a job?

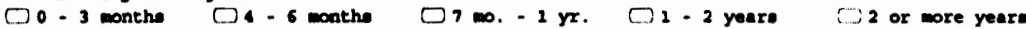


The Effects of a RJP 65

APPENDIX D

JOB PROFILE MEASURE 
- Think about the job of dispatcher you are applying for and read each of the following questions.

- Select the number on the scale which provides the moat accurate and objoctive description of the dispatcher job. - Darken the bubble on the following pege which corresponds to your anawer.

1. To what extent does the job require a person to work closely with other people (oither "clients," or people in related jobs in the organization)?

$\begin{array}{lll}\begin{array}{l}\text { Very little; dealing with } \\ \text { other people is not at all }\end{array} & \begin{array}{l}\text { Moderately; some dealing } \\ \text { with others is necessary. }\end{array} \\ \text { necessary in doing the job. } & & \text { Very muct; dealing with other } \\ \text { people is an absolutely essential } \\ \text { and crucial part of doing the job. }\end{array}$

2. How much autonomy is there In the job? That is, to what extent does the job permit a person to declde on hls or her own how to go about doing the work?

$\begin{array}{lll}\text { Very little; the job gives } & \text { Moderate autonomy; many } & \text { Very much; the job gives } \\ \text { a person almost no personel } & \text { things are standardized and } & \text { the person aimost complete } \\ \text { "say" about how and when } & \text { not under the control of the } & \text { responsibility for deciding } \\ \text { the work is done. } & \text { person, but he or she can make } & \text { how and when the work is } \\ & \text { some decisions about the work. } & \text { done. }\end{array}$

3. To what extent does the job involve doing a "whole" and identfiable plece of work? That is, is the job a complete ploce of work that has an obvious beginning and end? Or is it only a amail part of the overall piece of work, which is finished by other peoplo or by automatic machines?

The job is only a tiny part of
the overall piece of work;

4. How much variety ls there in the job? That is, to what extent does the job require a person to do many different things at work, using a variety of his or her stdils and talents?

$\begin{array}{ll}\text { Very little; the job requires } & \text { Very much; the job requires } \\ \text { the person to do the same } & \text { the person to do many differ- } \\ \text { routing things over and over } & \text { ent things, using a number of } \\ \text { again. } & \text { different skills and talents. }\end{array}$

5. In general, how algnificant or important is the job? That ls, are the results of the person's work likely to significantly affect the llves or well-being of other people?

$\begin{array}{ll}\text { Not at all significant; the } & \text { Highly significant; the } \\ \text { outcomes of the work are } & \text { outcomes of the work can } \\ \text { not likely to affect anyone } & \text { affect other people in very } \\ \text { in any important way. } & \text { important ways. }\end{array}$

6. To what extent do menegers or co-workers let the person know how well he or she is doing on the job?

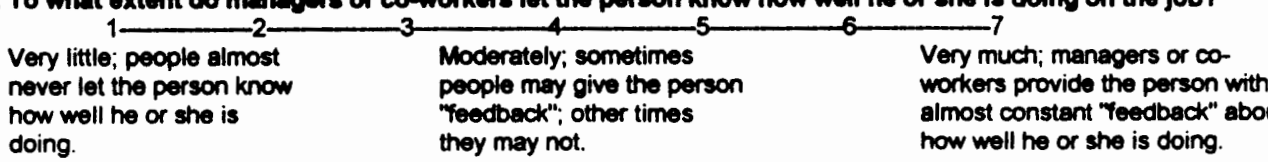

7. To what extent does doing the job lteelf provide the person with information about his or her work performance? That is, does the actual work iteelf provide clues about how well the person is doing, esido from any "foedback" co-workers or supervisors may provide?

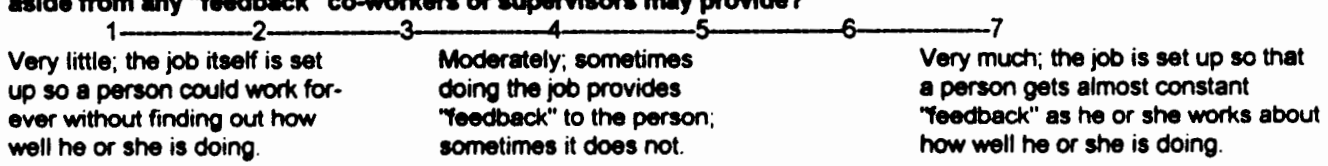




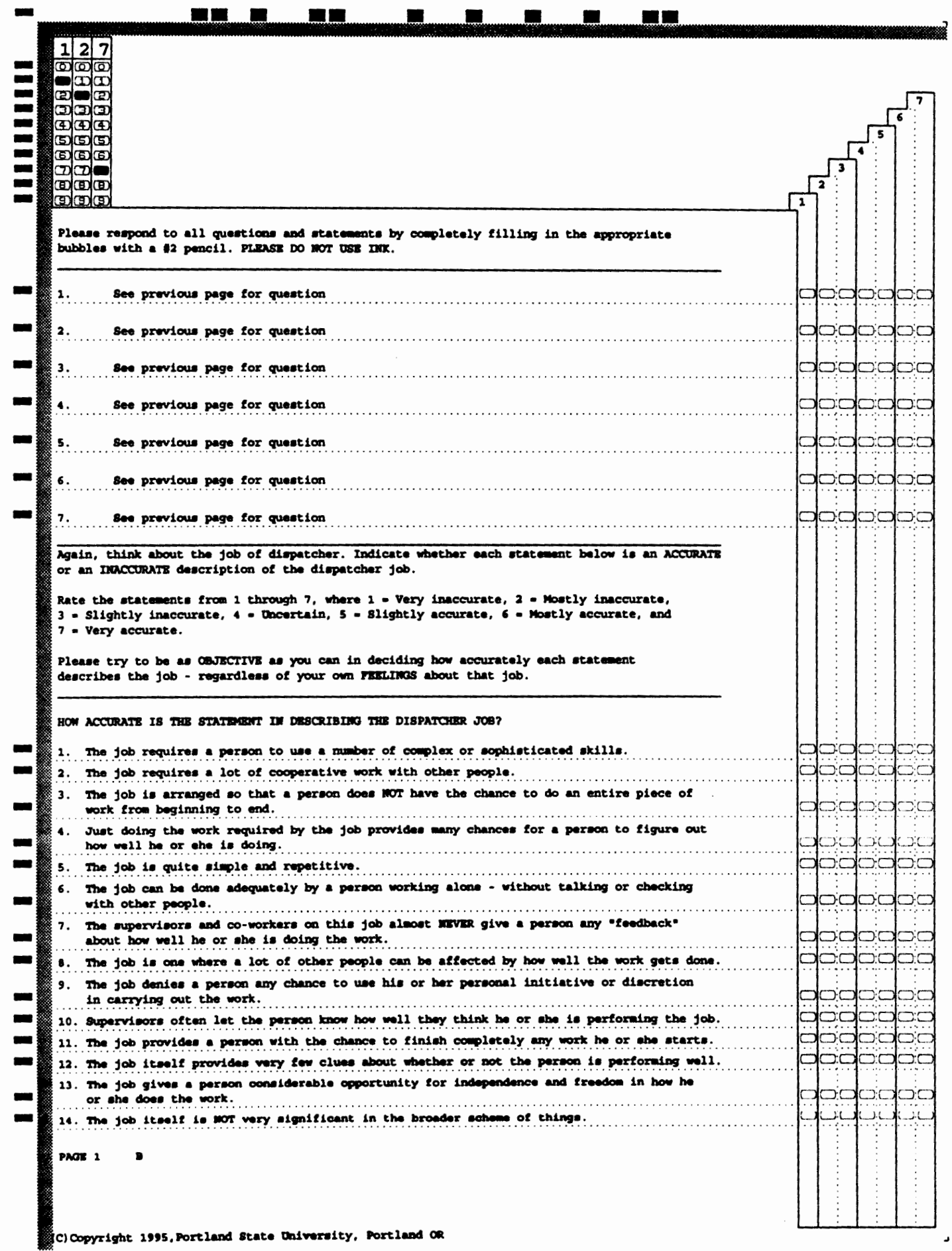




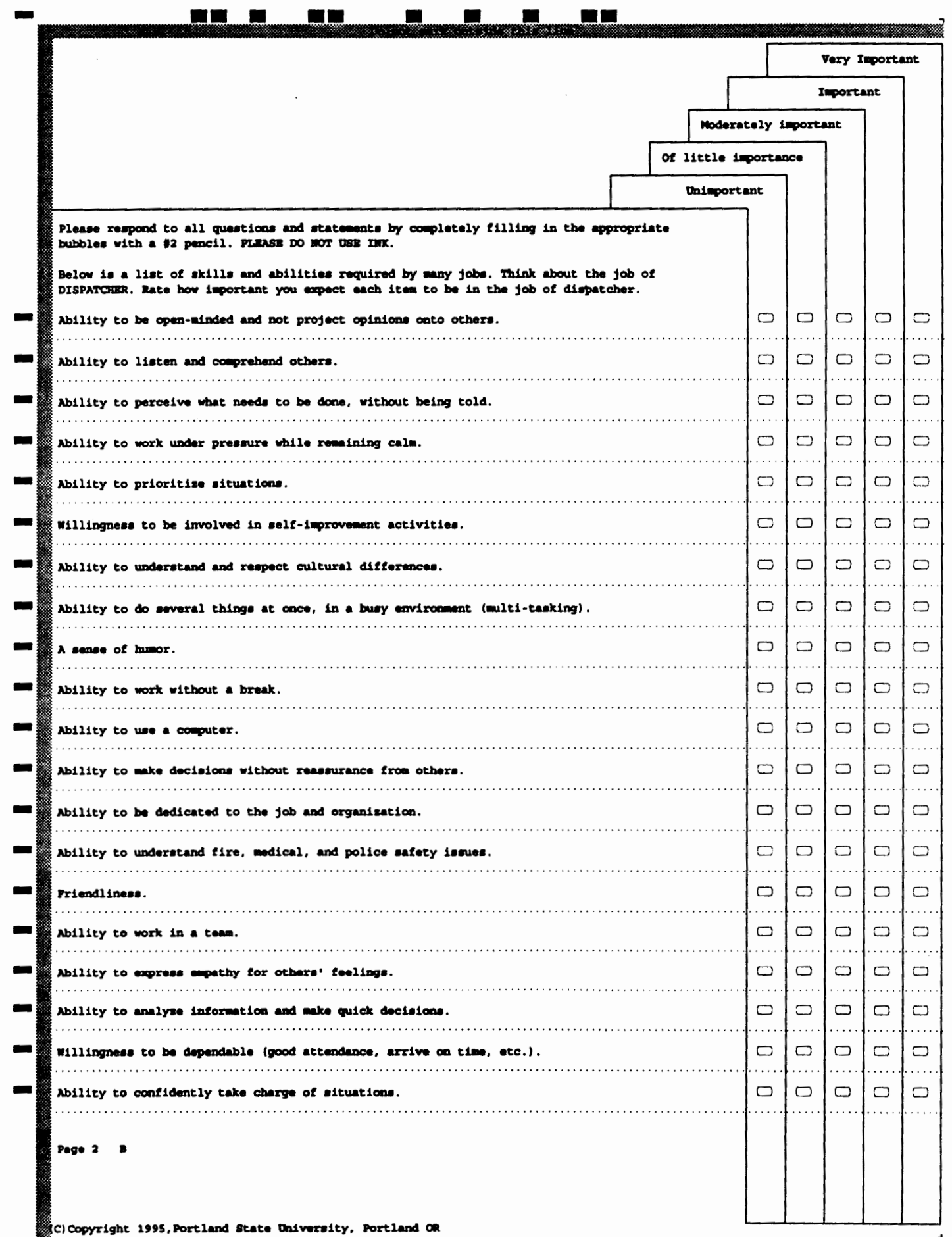




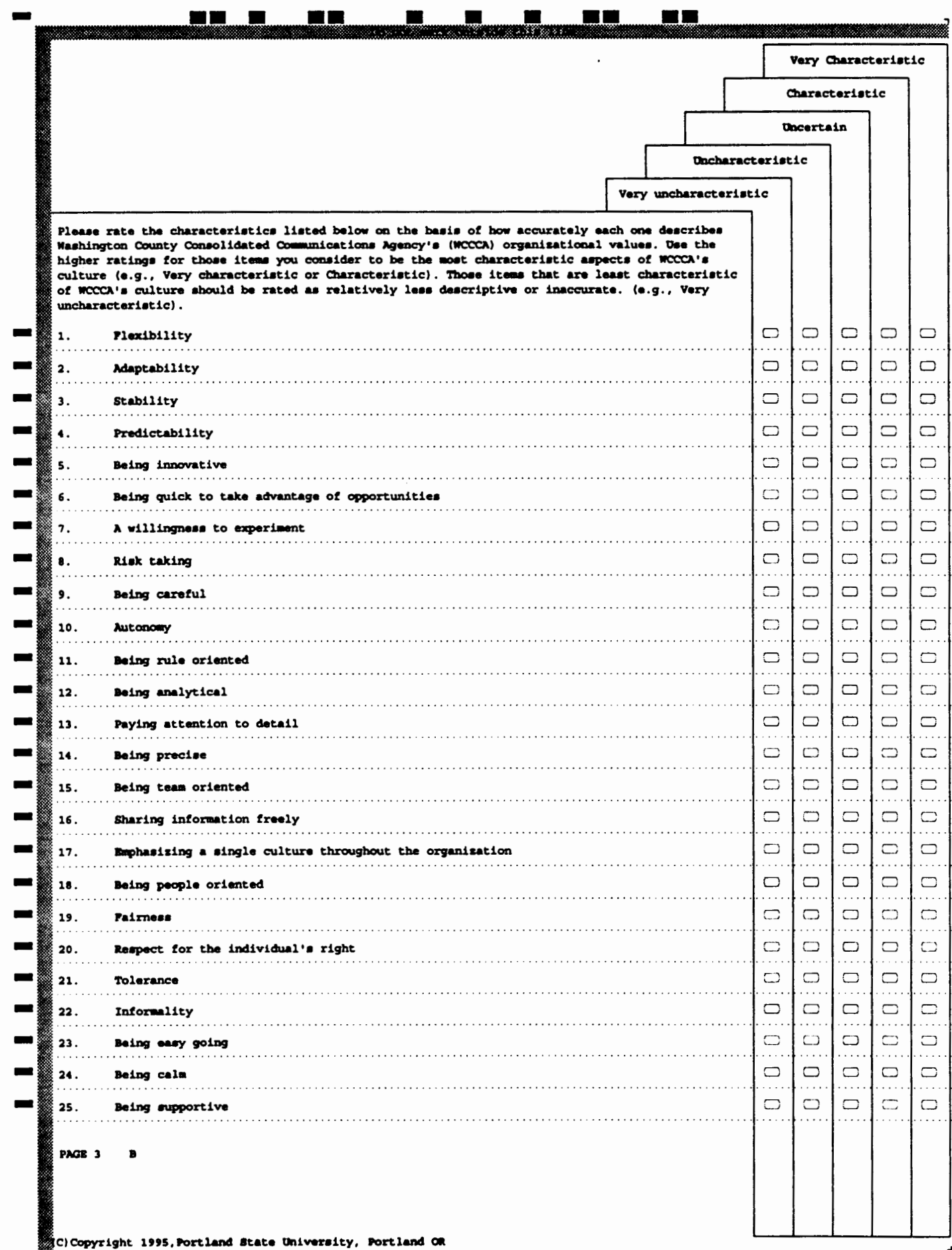




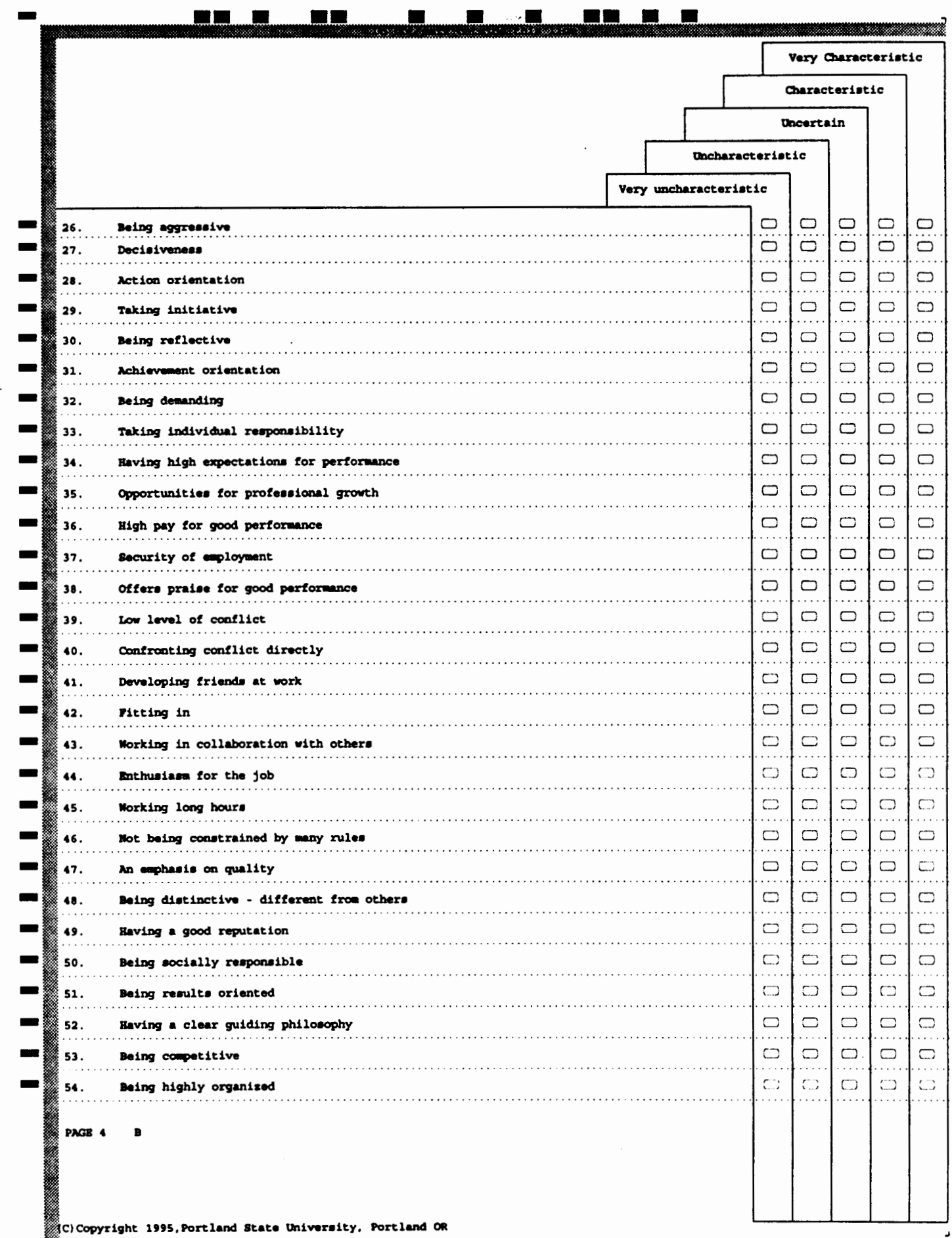


The Effects of a RJP 71

APPENDIX E

SELF-SELECTION MEASURE 


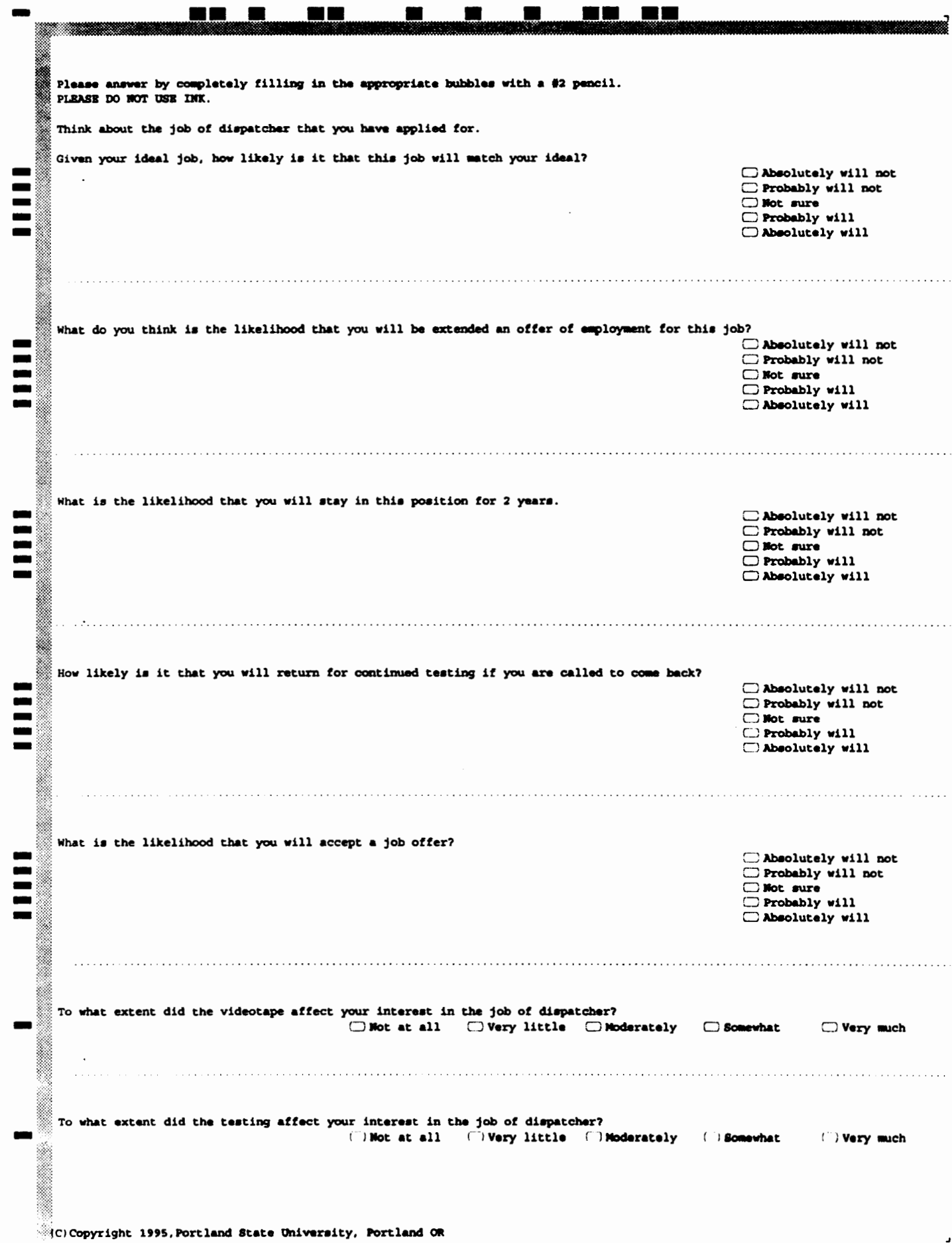


The Effects of a RJP 73

APPENDIX F

INFORMED CONSENT 


\section{INFORMED CONSENT FORM}

I, information and the selection process.

agree to take part in this research project on realistic

I understand that the study involves completing several questionnaires regarding my expectations about the job for which I am applying, my ideal job, and the likelihood of my acceptance of a job offer. I will also be asked to watch a videotape describing the job.

I understand that, to participate in the study, I will have to arrive early to the testing session and stay after the testing session. I also understand that my name will not be connected in any way with the data and that my answers to the research questions will not affect my chances of being hired for this dispatch job. I realize that the research is separate from the hiring process. No one at the agency at which I am applying, will see my responses to the research questions.

Participating in the study will give me more information about the job for which I am applying, and the study may help increase knowledge about selection that may help others in the future.

Melissa Burton has offered to answer any questions I have about the study and what I am expected to do.

In addition, she has promised that all information I give will be confidential because my responses will be linked by subject number, not by name. My name will only be used to mail me a follow-up questionnaire which will then be returned directly to the researcher.

I understand that I do not have to take part in this study, and that this will not affect my chances of being hired or my relationship with WCCCA. Furthermore, I may withdraw from the study at any time and it will also not affect my relationship with WCCCA.

I have read and understand the above information and agree to take part in this study.

Date:

Signature:

If you have any concerns or questions about this study, please contact the Chair of the Human Subjects Research Review Committee, Office of Research and Sponsored Projects, 105 Neuberger Hall, Portland State University, 503-725-3417. 
The Effects of a RJP 75

APPENDIX G

OCP CORRELATION MATRIX 


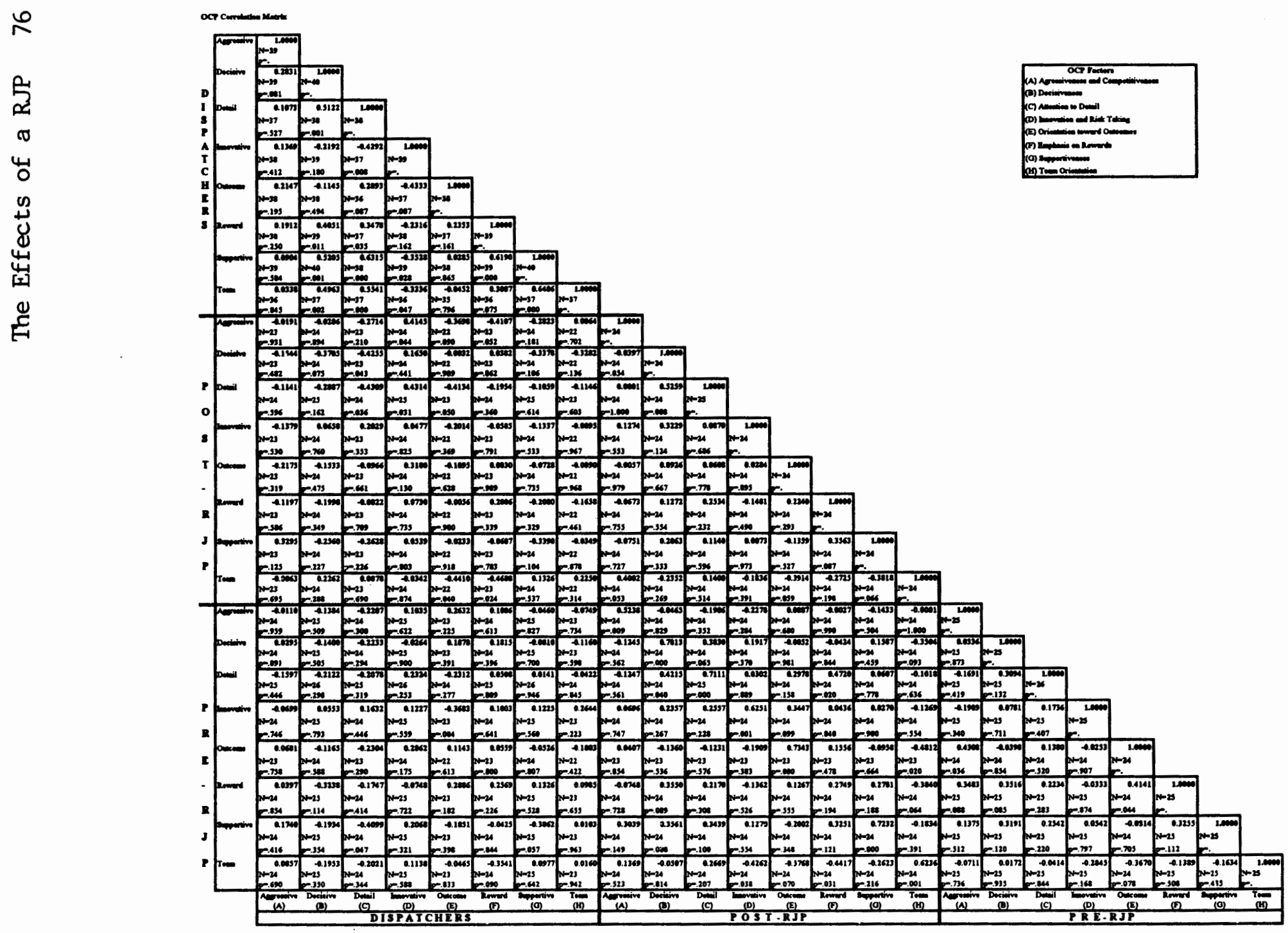

